\title{
Contradicciones entre hegemonía y subalternidad en la Costa Rica del siglo XXI. Una crítica a la concepción de democracia representativa de G. Sartori
}

\section{Esperanza Tasies Castro'}

Recepción: 1 de noviembre de 2015 / Aprobación: 14 de diciembre de 2015

\section{Resumen}

Este artículo analiza la relación que se establece, en el contexto del siglo XXI, entre aquellos actores político-partidarios que se agruparon desde posicionamientos "anti-neoliberales" y el conjunto de actores sociales que conformaron lo que se conoció como "Movimiento del No". Se trata de una investigación de carácter cualitativo, que analiza la producción discursiva y los posicionamientos políticos de estos actores sociales. El proceso conclusivo apuntó a la comprensión del carácter de la relación entre lo político y lo social. Así, se problematiza el carácter funcional del Estado y la llamada sociedad civil.

\section{Palabras clave}

Estado; hegemonía; subalternidad; expropiación/exclusión; movimiento social

\section{Abstract}

This paper analyzes the relationship established among political actors who gathered as supporters of "anti-neoliberal" positions and social actors who organized themselves in the so called "Movimiento del No" in the early $21^{\text {st }}$ Century context. It is a qualitative research that analyzes the discursive production and political positions of these social actors. The conclusive process aimed at understanding the nature of the relationship between the political and the social. The functional nature of the relationship between the State and the civil society is problematized.

\section{Keywords}

State; hegemony; subalternity; expropriation/exclusion; social movements

1 Costarricense. Máster en Sociología (Maestría Centroamericana en Sociología) por la Universidad de Costa Rica (UCR) y Máster en Psicopedagogía por la Universidad Estatal a Distancia (UNED). Coordinadora de la Sección de Antropología y Sociología de la Sede Occidente (UCR). Docente en la Sede de Occidente y en los Programas de Posgrado en Enfermería de la misma universidad. Correo electrónico: esperanzatasies@gmail.com 


\section{Resumo}

Este artigo analisa as relações estabelecidas entre os atores políticos que se reuniram como defensores de posições "anti-neoliberais" e os atores sociais que se organizaram no chamado "Movimiento del No" no contexto do século XXI. É uma pesquisa qualitativa que analisa a produção discursiva e posições políticas destes stakeholders. O processo de conclusão teve como objetivo compreender a natureza da relação entre o político eo social. É problematizada a natureza funcional da relação entre o Estado e a Sociedade Civil.

\section{Palavras chave}

Estado; Hegemonia; Subalternidade; Expropriação/Exclusão; Movimentos Sociais

as tesis que aparecen en este trabajo son el resultado de una investigación previa que analizó el complejo relacionamiento existente en la diversidad de actores sociales y políticos que llegaron a aglutinarse (desde espacios locales y nacionales) como movimiento de resistencia frente a la incorporación de Costa Rica al Tratado de Libre Comercio entre República Dominicana, Centroamérica y Estados Unidos de América, CAFTA-RD por sus siglas en inglés o, simplemente, TLC (Tasies, 2015).

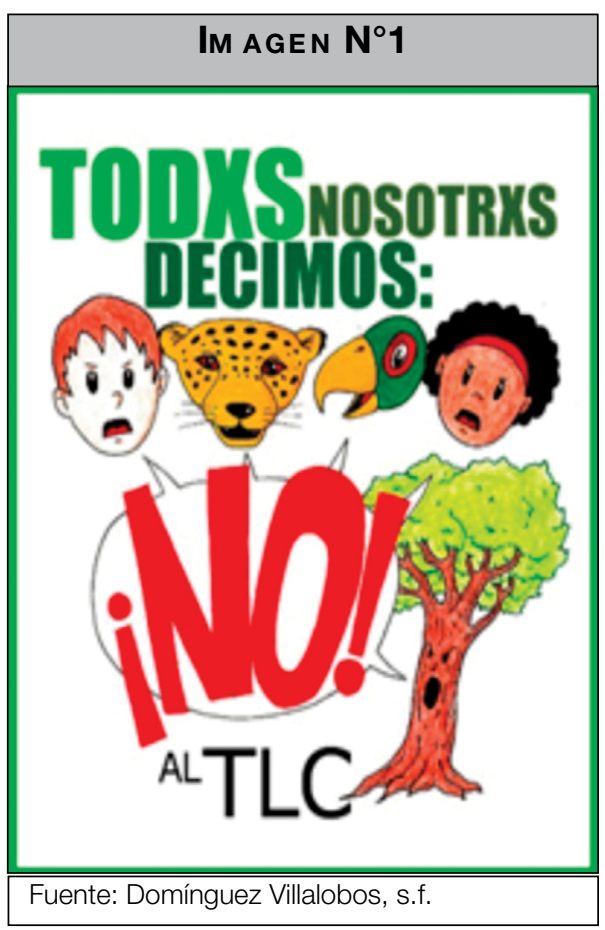

Desde un particular abordaje del objeto de estudio, se le confiere especial importancia al carácter de la relación entre lo que se considera político y lo que se considera social. Para ello se presta singular atención a las posibilidades de interpretación y ejecución por parte de los actores político-partidarios; en particular de los intereses y las necesidades de quienes tienen como ámbito de acción un espacio "no político", esto es, fuera de la esfera del Estado (actores sociales). Todo lo anterior se presenta en un contexto de "debilidad del vínculo representativo en las democracias latinoamericanas" (Raventós, 2008, p. 14). Así, este esfuerzo se dirige a fortalecer la comprensión de uno de los momentos más importantes de la historia reciente de Costa Rica, desde 
una perspectiva analítica distinta ${ }^{2}$ a la que han aportado otros antecedentes, cuyo objeto de estudio se ubica en el mismo periodo histórico. Este esfuerzo por indagar en las relaciones entre la esfera de lo político y la esfera de lo social se reconoce como punto de partida de una tarea compleja, puesto que aborda una relación histórica que resulta fundamental para el funcionamiento de la democracia liberal.

En términos conceptuales, se trata de una distinción de carácter funcional planteada en torno de la relación "esfera política-intermediación-sociedad". El esfuerzo analítico confronta la vigencia de la concepción liberal de democracia presente en el pensamiento del científico Giovanny Sartori (2002, 2003a, 2003b, 2005a, 2005b), quien define el régimen democrático formal desde una "serie de mecanismos representativos que permiten la transmisión del poder, y sobre todo el control y la limitación del mismo" (Sartori, 2003a, p. 137). Según este teórico de la Ciencia Política, la materialización del ejercicio democrático liberal requiere de una distinción entre gobernantes y gobernados, lo que ubica la relación entre actores políticos y actores sociales dentro de este campo que presupone un "proceso político entretejido de negociaciones" propia del gobierno representativo (Sartori, 2003a, p. 147).

Se trata entonces de una premisa central que debe ser confrontada con los hechos de carácter histórico que se analizan en el periodo que abarca esta investigación y que, en forma parcial, se presentan en este trabajo reflexivo, cuya importancia, debemos agregar, radica en que se profundiza en una relación básica para la continuidad de las instituciones que tutelan la democracia formal representativa. En ese sentido, explora en el campo de las probabilidades que tienen los partidos políticos para continuar reproduciendo la relación "Estado-Sociedad civil", por lo menos, en la forma que se llevó adelante hasta finales del siglo XX. Tal y como aclara el propio Sartori, la mediación política es vital para la reproducción del ejercicio hegemónico y define los sistemas de partidos como los "mecanismos representativos de trasmisión del poder" (Sartori, 2003a, p. 137). Esta mediación es una de las dimensiones centrales que explica la importancia de los partidos políticos y que reside, precisamente, en garantizar la viabilidad de la democracia representativa, como bien deduce el científico citado.

A pesar de que Sartori define la política "como autónoma y como causa generadora" y la "sociedad civil" como esfera pre-política, identificando a ese espacio entre ambas dimensiones "el nudo más difícil de desatar" (Sartori, 2002, p. 201), tal distinción no recoge ni permite ubicar una serie de actores, especialmente aquellos que se identifican como nuevos actores sociales en el

2 El estudio no brinda interpretaciones sobre la relación ciudadanía-democracia, sino que se ubica en la perspectiva analítica de Wallerstein (2004) y analiza el proceso de desintegración de los mecanismos de intermediación en la sociedad como producto de una tensión estructural del sistema-mundo. 
siglo XXI: tal es el caso de los "Comités Patrióticos"3 y otros, consolidados en el proceso de resistencia frente al CAFTA-RD.

En la concepción sartoriana de democracia se especifica la existencia de un sistema político con varios subsistemas, entre los que se encuentran dos espacios básicos para la democracia liberal: el subsistema de partidos políticos y el subsistema de los grupos de presión (Sartori, 2002, p. 220). De esta manera, el autor prevé la existencia de intereses corporativos, los que se materializan en la acción ejercida por aquellos actores denominados como "grupos de presión". Sin embargo, tal existencia solo está pensada como parte de un subsistema menor en jerarquía, dentro del sistema político que debe garantizar la gestión vertical de la vida política (Sartori, 2003a, p. 203).

Por más que las corporaciones gigantes, o también los poderes sindicales, lleguen a ser influyentes, ello no quiere decir que su poder sea "soberano" que esté sobreagregado al poder político. En la medida en que un sistema político funciona, las órdenes predominantes y vinculadoras erga omnes son y siguen siendo los dictados que emanan del propio dominio político (Sartori, 2002, p. 221).

Un esfuerzo teórico de confrontación frente al supuesto sartoriano, que le confiere autonomía a la política, necesariamente debe sopesar las implicaciones e imbricaciones de la exacerbación del "imperativo propio de la política" (Sartori, 2002, p. 209). En el actual contexto (refiere a la reestructuración e institucionalización neoliberal, la que es necesariamente unilateral por parte del ejercicio hegemónico). En caso contrario, una importante veta para analizar la legitimidad de la democracia formal representativa estaría siendo pasada por alto.

Se trata de la "puesta en cuestión" de la premisa sartoriana que le confiere autonomía y supremacía a la esfera política, al sistema de partidos y sobre lo social. Es preciso tomar en cuenta, que la funcionalidad entre ambas esferas se concreta en la representación que realizan los actores políticos, de los intereses y expectativas de aquellos grupos o conglomerados que demuestran confianza y se consideren representados. Es decir, se trata de una relación funcional dentro del vínculo Estado-mediación-"sociedad civil”.

Para el análisis del contexto del que se ocupa este artículo, se estableció (al momento de concretar el objeto de estudio) un tratamiento conceptual y metodológico para el abordaje específico del "declive de la confianza en las instituciones representativas", cuyo corolario no puede verse en forma aislada, puesto que vincula los nichos y formas de acumulación capitalista en el siglo $\mathrm{XXI}$.

3 Los Comités Patrióticos son los actores principales del conflicto social que polarizó a la sociedad costarricense en la primera década del siglo XXI. Es importante acotar que tienen su base en lo local y su proceso organizativo es informal y espontáneo; se trata de unidades básicas de acción inmediato o de lo local. 
Las necesidades de reproducción del capital y el agotamiento de las fuentes de extracción de la riqueza explican la profundización de la reestructuración neoliberal, la cual se lleva adelante mediante un proceso sostenido de expropiación/exclusión en el tiempo y en el espacio que se extiende a lo largo de varias décadas ${ }^{4}$. El mencionado proceso ha requerido de una radicalización del ejercicio hegemónico, lo que a su vez ha debilitado los canales y actores formales o contra-partes de negociación, en lo que algunos autores y autoras ubican como "Estado-sociedad civil".

Cuando se conceptualiza el ejercicio hegemónico radicalizado, se hace referencia a la radicalización de posiciones que mostró el bipartidismo en cuanto a la implementación de la reestructuración neoliberal. Los grupos hegemónicos, en control del aparato del Estado a finales del siglo $\mathrm{XX}$, principios del siglo $\mathrm{XXI}$, tomaron posturas de unilateralidad, $y$ los procesos de negociación que se conocieron como "Estado-Sociedad Civil", abiertos en momentos de conflicto social, no tuvieron resultados

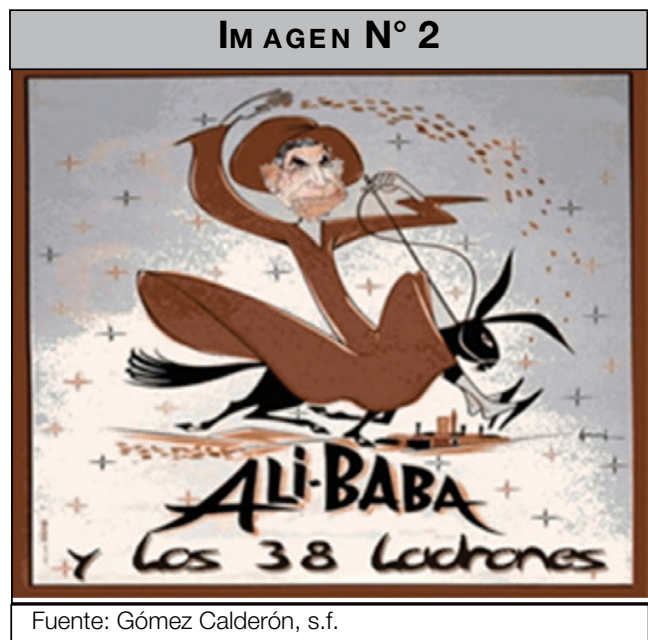
positivos para los grupos o sectores afectados por las medidas neoliberales ${ }^{5}$. En ese sentido, el concepto ejercicio hegemónico radicalizado da cuenta del deterioro de los mecanismos para dirimir el conflicto.

No obstante, el proceso conceptualizado como radicalización del ejercicio hegemónico tiene aparejado otro fenómeno de alto costo para la llamada democracia representativa, se trata de la pérdida de legitimidad frente a amplias capas de la población. Es precisamente ese espacio de ilegitimidad el que dio lugar a la ruptura del bipartidismo y emergencia de los actores político-partidarios "antineoliberales", quienes, desde el "andamiaje" reflexivo de este artículo, se encuentran en la contradicción hegemonía-subalternidad. La legitimidad debe ser interpretada como la capacidad del sistema de partidos y sectores que controlan el aparato estatal para "articular la voluntad democrática" a partir de transmitir credibilidad a amplios sectores de la población. Todo esto alrededor de "los intereses, aspiraciones y orien-

$4 \quad$ La mayoría de las investigaciones alrededor de este tema ubican el arranque del proceso de expropiación/ exclusión a principios de la década de 1980 y reconocen un salto cualitativo del mismo en el año 1995, momento en que el bipartidismo logró acuerdos políticos para profundizar las medidas neoliberales.

5 La investigación que fundamenta este artículo analizó conflictos sociales emblemáticos, Combo ICE, "Limón en lucha", conflicto contra RITEVE, (2002-2004) y ninguno de ellos tuvo salidas que incluyeran las demandas de los grupos involucrados (Tasies, 2015, p. 81). 
taciones políticos sociales" que se plantean desde los órganos decisorios del Estado

Partiendo del hecho de que la legitimidad o ilegitimidad pueden implicar e imbricar muchas dimensiones de la realidad, se aclara que el uso que aquí se hace de este concepto refiere únicamente a la esfera política y de forma específica a la institucionalidad democrática que canaliza el Estado. Es así como se recurre a los esfuerzos analíticos propuestos por Massimo Modonesi (2010), en el sentido de estructurar un campo analítico de las subjetividades políticas de una época concreta, dicho campo de análisis permite valorar las experiencias de los actores involucrados en los procesos de resistencia social. En la perspectiva de Modonesi (2010, p. 20), el campo de la experiencia le confiere "forma y especificidad" a la subjetividad de los actores.

De esta manera el ejercicio hegemónico unilateral, que radicalizó los procesos de expropiación/exclusión propios del capitalismo tardío, generó un espacio subjetivo, en el que los actores se remiten al campo de la subalternidad; en dicho campo de subjetivación de experiencias "dispares y aparentemente desconectadas de subordinación" (Thompson, 1989, citado por Modonesi, 2010, p. 21) se expresa la dimensión que se podría interpretar como "sociopolítica", por cuanto revela posicionamientos políticos de actores que se "mueven" fuera o a contrapelo de las instituciones de la democracia formal. El Mapa Reflexivo No. 1 analiza los resultados de la investigación en cuanto a los procesos de resistencia social ${ }^{6}$.

La comprensión del ascenso y de las expectativas reales de acceder al control del aparato del Estado costarricense por parte de actores políticos, distintos al bipartidismo y auto-denominados "anti-neoliberales", debe pasar por el análisis de la radicalización del ejercicio hegemónico a partir del Pacto Figueres-Calderón?, en el año 1995. Es precisamente este ejercicio, el que abre el espacio para la constitución de la forma de subjetivación subalterna, documentada en los trabajos de Máximo Modonesi (2010). La identificación del adversario, propia de la existencia de movimientos sociales específicos, explica una forma de subjetivación que es resultado directo del ejercicio hegemónico vertical y radicalizado al que se hace referencia en este trabajo. Es importante consolidar en esta introducción el objeto que se discute y, por ende, la perspectiva teórica que prioriza como razonamiento sociológico.

6 Tanto los gráficos como los cuadros elaborados en la investigación que da vida a este artículo, son el producto de la recopilación de posicionamientos políticos emitidos por todos los actores involucrados; se diseñaron a partir de la técnica de codificación axial (Strauss, A., \& Corbin, J. 2002), se trata de una codificación detallada que emerge de las ideas centrales presentes en la documentación analizada.

7 Se trata de acuerdos para implementar las medidas de condicionalidad cruzada del Fondo Monetario Internacional (Bermúdez, 2004). 


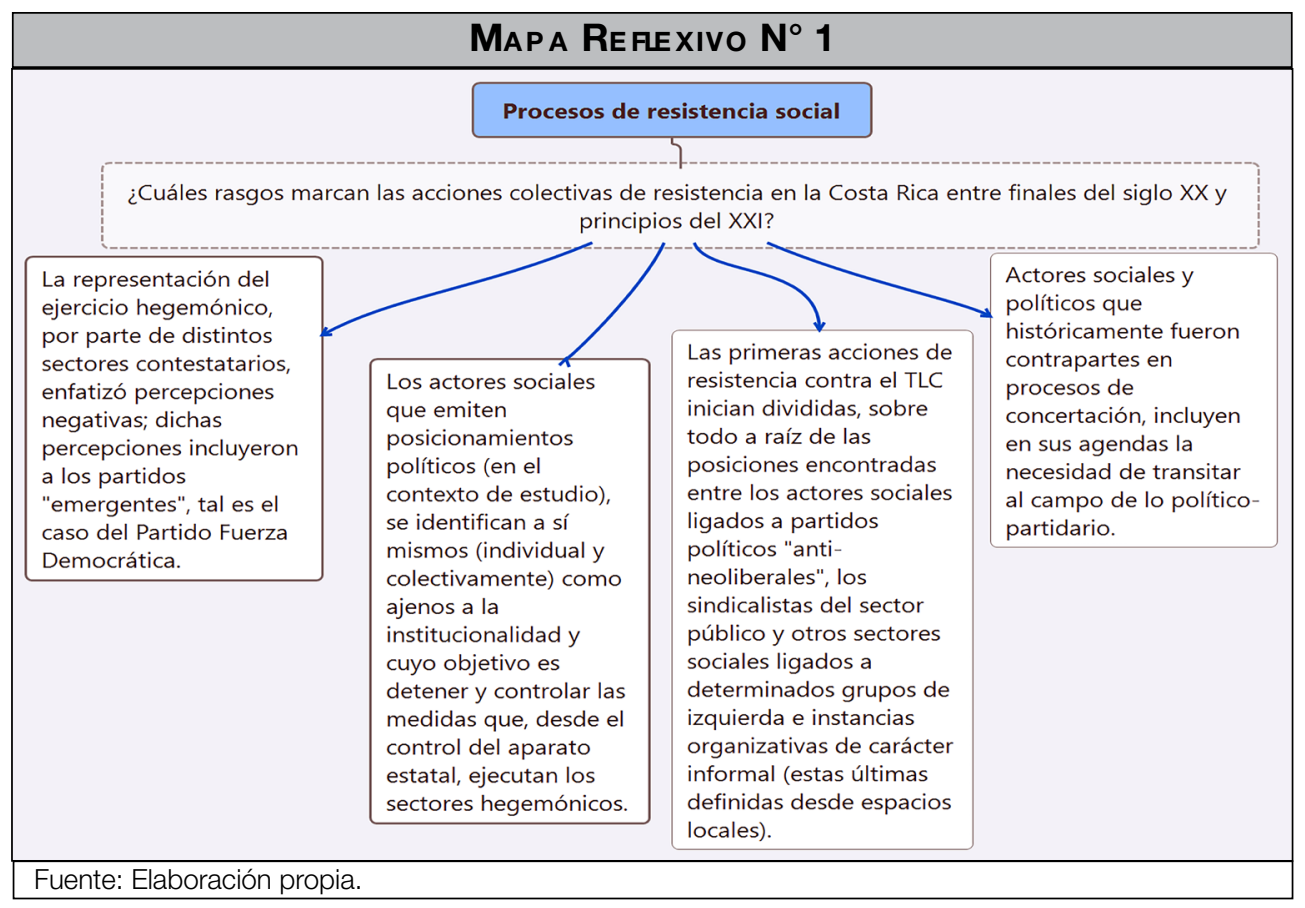

La investigación se ubica en la tradición teórica que discute la relación entre lo hegemónico y lo subalterno. Esta tradición, originalmente gramsciana, es retomada por el teórico Máximo Modonesi (2010). Para este último autor, el uso del concepto subalternidad "permite centrar la atención en los aspectos subjetivos de la subordinación en un contexto de hegemonía" (Modonesi, 2010, p. 36). El Mapa Reflexivo № 2 analiza la relación establecida entre lo hegemónico y lo subalterno, la que explica la radicalización de posturas políticas alrededor de las tesituras del "NO" y el "Sl".

La relación entre lo hegemónico y lo subalterno revela un límite estructural. La radicalidad de este ejercicio de poder unilateral expresa límites para materializar los objetivos de reproducción del capital en sus expresiones transnacionales y nacionales, y, al mismo tiempo, conservar la legitimidad del grupo hegemónico ligado al bipartidismo costarricense. Es precisamente esta condición la que abre el espacio político para la participación de alternativas partidarias autodenominadas como "anti-neoliberales".

En el centro analítico de un necesario debate con perspectiva sociológica, se encuentran las posibilidades de representar y dar salida político-partidaria a una amplia gama de actores, quienes podrían dejar de tener una "perspectiva recíproca" con el sistema democrático-formal de carácter liberal en el

8 La incorporación de Costa Rica a la zona de libre comercio (CAFTA-RD para sus siglas en inglés) o su rechazo se polarizó en ese momento histórico como "Movimiento del No" y "Movimiento del Sí". 
sentido que apunta Touraine (1994, p. 47), cuando sostiene la emergencia de un proceso de "desocialización" de sectores de la población con el sistema de partidos y con la institucionalidad garante de la democracia formal. El proceso de ilegitimidad que enfrenta el ejercicio hegemónico y las transformaciones que sufre el Estado a favor de la modalidad de acumulación capitalista, a la que se hará referencia, delimita el tipo de acceso que tienen y tendrán las opciones partidarias anti-neoliberales (actores políticos) cuando del poder político se trata.

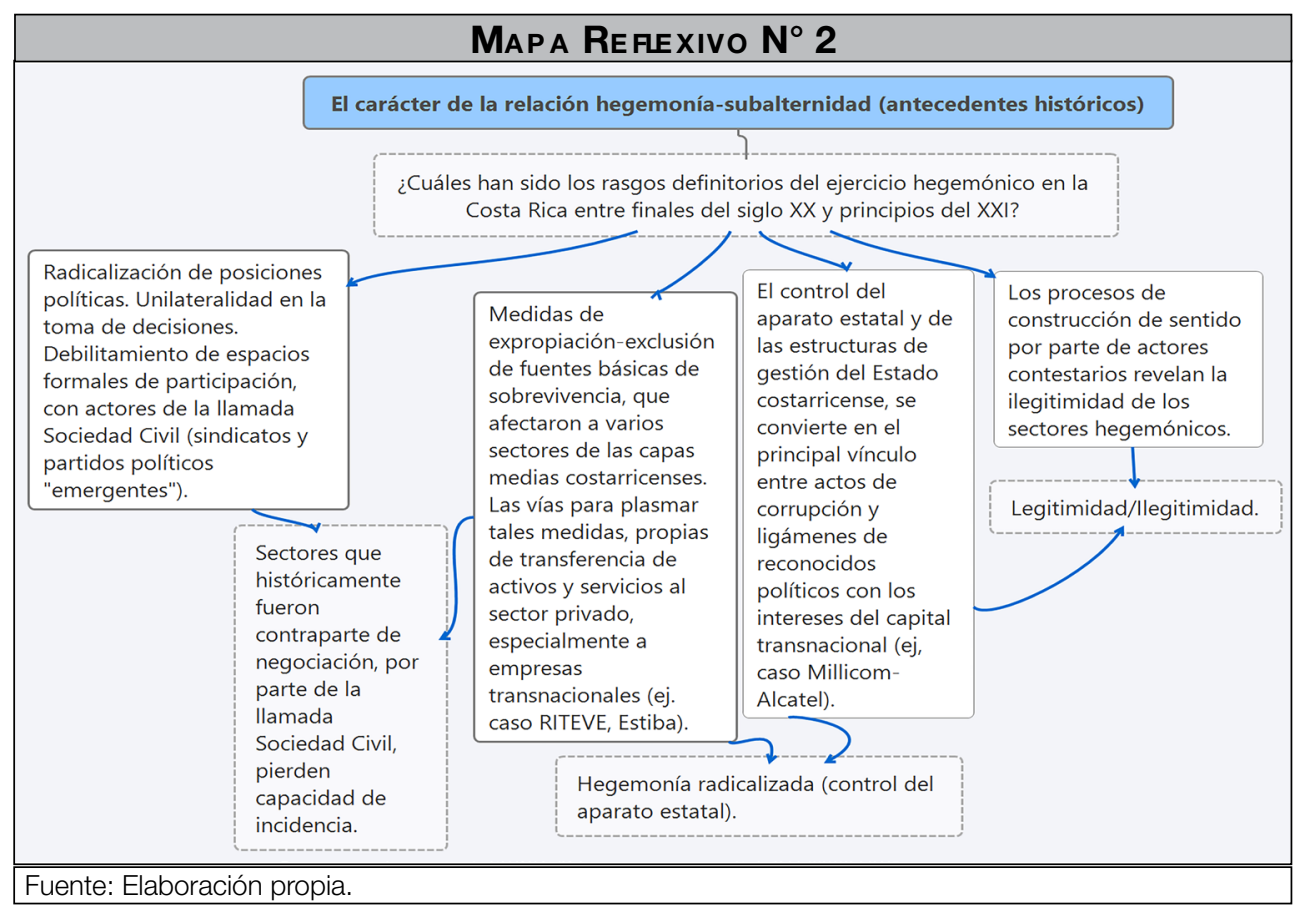

Tómese en cuenta que las opciones partidarias anti-neoliberales se decantaron al calor de las acciones colectivas de resistencia, de carácter acumulativo, que involucraron a actores sociales, quienes por sus formas organizativas y de participación son caracterizados como "núcleos desnormativizados", tal y como lo documenta el antropólogo Jeremy Raymer (2008) en investigación que tiene como antecedente este trabajo. Desde Raymer podemos afirmar que el ligamen territorial de estos núcleos, a los que posteriormente se conoció

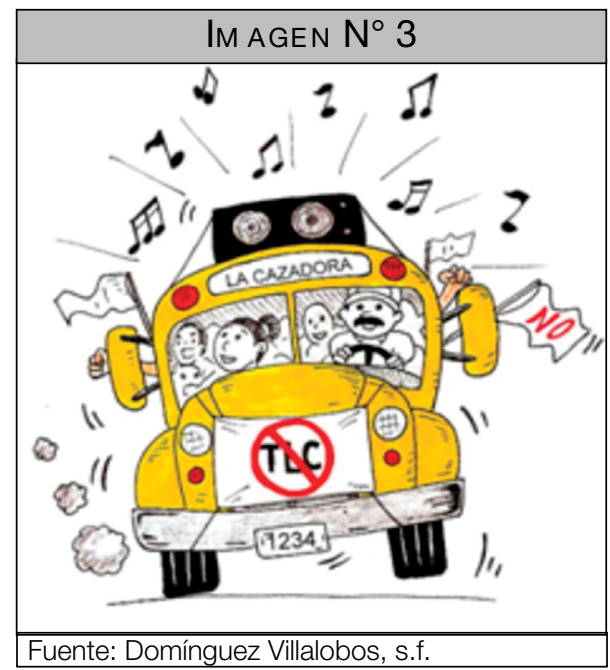


como Comités Patrióticos, era eminentemente local al igual que sus resortes de movilización y convocatoria. Este detalle no deja de ser importante si se toma en cuenta que la lógica de los partidos políticos solo apunta a lo local como si se tratará de una extensión de dominio del partido.

Así las cosas, se comparten algunos resultados de una investigación que analizó y contextualizó los posicionamientos políticos de dos grandes conglomerados de actores, diferenciados por esferas e intereses distintos. Por un lado, los llamados partidos "anti-neoliberales"9 y, por el otro, un conjunto de actores de origen local, quienes, en el proceso de acumulación de descontento social, se manifestaron con nitidez en las acciones colectivas de resistencia frente a la privatización de la telefonía celular y la electricidad, desde el año 2000, movimiento al que se conoció como "Combo ICE".

Con el objeto de desarrollar un análisis comparativo de las posturas políticas y las valoraciones frente al contexto (carácter radicalizado y unilateral de la hegemonía del Estado costarricense), se sistematizaron más de 500 documentos emitidos por los dos grandes grupos de actores (políticos y sociales) que conformaron el "No", en oposición a la incorporación de Costa Rica al CAFTA-RD ${ }^{10}$. Es precisamente en ese espacio de discusión en el que se centra este esfuerzo reflexivo, el cual parte de una investigación que cubrió un amplio periodo de relacionamiento entre actores políticos y actores sociales.

En el momento de construcción del objeto de estudio, se ubicaron dos tipos de perspectivas para abordar el relacionamiento entre actores sociales y actores políticos en el contexto del capitalismo tardío. De un lado, tenemos a aquellos estudios que tratan el tema del deterioro del vínculo entre lo político y lo social como expresión de una crisis de representatividad, prescribiendo el fortalecimiento de la institucionalidad democrático formal. De otro, se encuentran los estudios que analizan el complejo relacionamiento que nos ocupa, desde las prácticas hegemónicas y las respuestas subalternas, en la intención de analizar la vigencia de la institucionalidad democrática formal y las vertientes teóricas que conciben lo político y lo social como relación funcional.

El segundo nodo problematizador citado ubica claramente las intenciones de esta investigación: un particular abordaje del objeto, que confiere especial importancia al carácter de esta relación entre lo hegemónico y lo subalterno en el nuevo siglo, especialmente en las posibilidades de interpretación y ejecución por parte de los actores político-partidarios, de los intereses y necesidades de

9 Se dio seguimiento a los partidos políticos que participaron dentro del "Movimiento del No", (Frente Amplio, Alianza Patriótica y Partido Acción Ciudadana) bajo la categoría "anti-neoliberales" dado la complejidad de sus denominaciones y sobre todo por la falta de adscripción de su definición ideológica con una clase social específica.

10 El enfoque cualitativo ahondó en la producción discursiva de ambos grupos de actores y tuvo como objeto analítico las fuentes primarias emitidas por los mismos. Los posicionamientos fueron sometidos a análisis discursivo y comparativo, para establecer los puntos de encuentro o desencuentro. 
quienes tienen como ámbito de acción un espacio "no político", esto es, fuera de la esfera del Estado (actores sociales).

Como resultado de ello, la investigación puede aportar dos importantes grupos de conclusiones en el campo de la relación que existe entre lo que se considera político y lo que se considera social:

a. Las tendencias del contexto y las particularidades que explican las posturas de los actores involucrados.

b. La identificación de los nodos problemáticos y distinción entre los fines y medios que privilegia cada grupo de actores, en relación con el ámbito en el que dirime su accionar (lo político y lo social).

Se trata de dos lógicas, referidas a ámbitos, fines y medios distintos: por un lado, los actores políticos priorizan las vías formales e institucionalizadas para dirimir el conflicto social y, por el otro, los actores sociales, en gran medida, se mueven en ámbitos menos formales y con una amplia gama de repertorios de lucha, cuya lógica, no siempre está dirigida a acceder al control del aparato estatal.

\section{Sobre el contexto que explica la acumulación social que se conoció como "Movimiento del No"}

Una de las características principales de la hegemonía, expresa y materializa la apropiación de los mecanismos de dirección política de la sociedad, lo que va mucho más allá de la dirección del Estado. Esos sectores hegemónicos no solo son los dueños de los medios de producción, sino que organizan desde lo material e ideológico la cotidianidad de determinada sociedad. La polarización social que se conoció como "Movimiento del No" es una respuesta directa al ejercicio hegemónico radicalizado y unilateral, en tanto este logra materializar formas de acumulación (de capital) absolutamente necesarias para su reproducción, lo cual a su vez implica la multiplicación de las fuentes del conflicto y la polarización de los procesos de resistencia social. Algunas de las principales características del contexto al que se hace referencia, expresan serios límites para la reproducción del control político por parte del bipartidismo costarricense:

a. Incapacidad de los entes estatales competentes para dar respuestas favorables a las(os) actores sociales que se enfrentan a inversionistas extranjeros.

b. Ligamen de las empresas o medidas de los inversores extranjeros con determinados sectores del capital nacional o bufetes ligados a los grupos hegemónicos en el país.

c. Participación de los grandes medios de comunicación en defensa de la inversión extranjera como única vía para el desarrollo. 
d. Relaciones claras y comprobadas entre accionistas nacionales de empresas concesionarias de servicios, otrora públicos o en ejercicio de pequeñas empresas nacionales, con campañas y financiamiento del histórico bipartidismo costarricense ${ }^{11}$.

e. Canales de negociación inexistentes y cuando se abren no tienen salidas que incluyan las demandas de los grupos o actores que platean tales demandas.

Un análisis de algunos conflictos sociales emblemáticos ${ }^{12}$, que movilizaron a muchos sectores sociales en el contexto referido, permite establecer tendencias que marcan el deterioro de los mecanismos de negociación y la forma en que los sectores que han estado controlando el aparato estatal han dirimido el conflicto social. Así, la investigación dio cuenta de amplios y diversos sectores que, en el proceso de acumulación de descontento social conocido como "Movimiento del No", definían el contexto en cuestión como resultado de la concreción del modelo de exclusión/expropiación que caracteriza a la reestructuración neoliberal; así lo hacían ver en sus posicionamientos políticos.

La Federación Centroamericana y del Caribe de Avicultores hizo coincidir una reunión aquí con el inicio de las negociaciones que eventualmente conduzcan a la firma de un tratado de libre comercio (TLC) con Estados Unidos.

Este sector y los porcicultores, manifestaron ya posiciones regionales de consenso. Su petición es quedar fuera de la negociación del acuerdo, pese a que Estados Unidos ha dicho que todo está sobre la mesa (La Nación, 28 de enero de 2003).

De esta manera, el análisis de lo subalterno permite identificar y referenciar la construcción de determinada subjetividad política frente a una relación de dominación (hegemonía). El uso del concepto remite al análisis de procesos, niveles y dimensiones, situaciones y momentos, que son manifestaciones de subalternidad frente al ejercicio hegemónico (Modonesi, 2010).

Es precisamente este contexto de contradicción el que abre el espacio para la participación de otras opciones partidarias, entre las que se encuentran los tres actores políticos que conforman la unidad analítica de esta investigación. De igual manera, dicho contexto determinó las características del escenario en el que se daría la relación de estos actores políticos con los grupos e individualidades que venían acumulando descontento con el proceso de expropiación-exclusión al que se hace referencia, mismo que da sus primeras muestras con agudos procesos de polarización social en varios momentos de la primera década del Siglo XXI (en referencia al "Movimiento del No").

11 Para la comprensión de los intereses imbricados entre lo público y lo privado, se utiliza como fuente secundaria, los datos aportados por el investigador Randall Blanco (2010), quien documenta con precisión las redes imbricadas ligando intereses público-privados.

12 La investigación sistematizó los principales conflictos sociales entre 1996-2004 (Tasies, 2015, p. 73). Los desenlaces revelaron el escaso y nulo espacio de negociación para los actores involucrados. 
Se explica así la emergencia de alternativas partidarias (Partido Acción Ciudadana, Partido Alianza Patriótica y Frente Amplio) como producto del desgaste de los partidos políticos que eran o son representativos de sectores hegemónicos. Estos últimos, tuvieron un gran protagonismo en la aplicación de las medidas neoliberales que trastocaron la lógica del Estado-nación hacia posturas acordes con los lineamientos aperturistas de los Organismos Financieros Internacionales (en adelante OFls) y la Organización Mundial del Comercio (OMC).

\section{Sobre el carácter del Estado con posteridad a la década de 1980}

Este esfuerzo reflexivo ubica al Estado en las funciones históricas que ha tenido en las sociedades capitalistas. Igualmente, se le conceptualiza en términos de la naturaleza que le confiere la transición acaecida a partir de la década de 1980 (reestructuración neoliberal) y que se ha extendido hasta el presente (segunda década del siglo XXI). Ambos aspectos son fundamentales para el análisis de las relaciones entre actores políticos y actores sociales, en tanto terreno priorizado para la mediación en la democracia formal liberal. Esta ubicación en el carácter del Estado, como producto histórico y concreción temporal, responde a la necesidad de comprender las modalidades coyunturales de reproducción del capital. En este caso, se trata de una fase de descenso del capital que requiere de esa forma de radicalización a la que se conoce como neoliberalismo para alcanzar la acumulación en un contexto de agotamiento de muchas de las fuentes de extracción de riqueza.

Las funciones primordiales del Estado devienen precisamente de la lógica de "las intervenciones de múltiples unidades de capital" que no producen "la naturaleza social necesaria" (Mandel, 1979), esto es, para la existencia de la vida social. En la sociedad capitalista, el Estado, si bien es un producto histórico, requiere ubicarse "al margen y por encima de la Sociedad Civil"13 y al mismo tiempo, tal y como lo define Mandel (1979), debe cumplir una función que le es negada al capital por su propia naturaleza expansiva y concentradora: la realización de la vida social, de la cual es garante el aparato estatal.

Es importante tomar en cuenta, a esta altura de la reflexión, que afirmamos aquí que aquellos partidos políticos que se enfrentan a la contradicción entre hegemonía y subalternidad han llegado a dicha situación debido a sus esfuerzos por acceder a los mecanismos de dirección de la sociedad, entre ellos, el aparato del Estado, el cual se reviste de esterilidad en este contexto. Se trata de un Estado en el que se ha institucionalizado el pensamiento que acompaña a la reestructuración neoliberal. Un Estado debilitado e ilegítimo ante un amplio sector de la población, tal y como lo demostraron conflictos emblemáticos

13 Este argumento no puede analizarse en forma aislada de la perspectiva liberal con la que Sartori define la relación dicotómica entre Estado y Sociedad Civil. 
entre los que podemos mencionar el conjunto de acciones colectivas, masivas y secuenciadas, que se conoció como "Combo ICE", o las dos grandes movilizaciones sectoriales que pretendían el retiro del monopolio conocido como RITEVE, en los años 2002 y 2004 (Tasies, 2015, p. 118).

En la fase de ascenso del capital, posterior a la Segunda Guerra Mundial y que se extendió hasta finales de la década de 1970, la mayoría de los Estados nacionales crearon mecanismos de concreción para las demandas de los sectores subalternos en el orbe, proceso que fue producto de la sobre-acumulación. Mandel sostiene que esta expansión, posterior a la Segunda Guerra Mundial, fue posible en razón de que el capital provocó "una desviación sustancial de ingresos sociales" (Mandel, 1979, p. 467) ${ }^{14}$-acaecida en el periodo histórico del Estado Interventor. Las características particulares, keynesianas, de esta modalidad de hegemonía desde el Estado, fueron el resultado y conjunción de múltiples factores sociales, políticos y culturales. Sin embargo, fue la etapa expansiva del capital, tal como la llama dicho autor, la que permitió la inversión social que hizo posible que se conociera a ese Estado bajo el adjetivo de benefactor ${ }^{15}$.

Se hace necesario ubicar, en términos históricos, la transición del Estado Interventor al Estado Neoliberal, en tanto el accionar y relacionamiento de los actores políticos y sociales que analizó esta investigación no se produce en el vacío, sino frente a esta última forma de Estado. ¿Qué pertinencia conceptual tiende a calificar como neoliberal al esquema de Estado que se ha decantado desde principios de la década de 1980 en Costa Rica? La definición remite a las reformas administrativas que mantienen entre sí una lógica y coherencia que deviene en un conjunto de supuestos, tanto por parte de las personas que ocupan cargos públicos con poder de decisión en la esfera administrativa del Estado como en el corolario de las disposiciones de los OFIs (Banco Mundial, Fondo Monetario Internacional y Banco Interamericano de Desarrollo).

Una definición para el tipo de Estado que sirvió de telón de fondo para la relación entre actores políticos y actores sociales dentro del espacio simbólico de oposición al TLC (CAFTA-RD), y que se conoció como "Movimiento del No", requiere de una distinción entre el Estado Interventor, al que erróneamente se ha llamado "Estado Benefactor", y el Estado que se decanta desde finales de la década 1970 y que es el producto de la condicionalidad cruzada entre los OFIs y los sectores hegemónicos costarricenses.

Para efectos de esta investigación, se caracterizaron bajo el concepto de Estado Neoliberal una serie de supuestos, rasgos y formas de la gestión pública que agrupan y definen un proceso de reformas administrativas dirigidas

14 Lo que no implica que se afirme que todos los Estados nacionales del orbe cumplieran tales funciones, tipificadas como sociales, en igual extensión e intensidad.

15 En este contexto la reproducción del capital tiene como imperativo la acumulación a partir de la expropiación. La lógica keynesiana, no se encuentra en discusión para los sectores hegemónicos. 
a trastocar la lógica intervencionista de la gestión estatal, la cual había sido asumida por el Estado con posteridad al conflicto económico-político-militar acaecido en Costa Rica durante la década de 1940.

Por su parte, el carácter del Estado Interventor fue el producto de un acuerdo tomado por los actores principales relacionados con el conflicto económicopolítico-militar de la década de 1940 en Costa Rica. Al calor de ese proceso histórico, la Constitución Política termina por incorporar, en 1949, una serie de reformas sociales (CCSS, universidades) y económicas (como es el caso de las empresas del Estado), las cuales hoy son consideradas "obsoletas" por parte de aquellos sectores hegemónicos que vienen controlando el aparato estatal desde hace varias décadas.

Es importante aclarar que las reformas constitucionales con posteridad a la década de 1950, en el nivel internacional, representaron, de acuerdo con Subirats (1992), un proceso de democratización de las Constituciones Liberales. Dicho proceso requirió superar los supuestos del "iusnatural”, para refundar los Estados nacionales para la conformación de un Estado Social, el cual, según el mismo autor, presupone ciertos derechos y garantías de carácter universal. Esta reforma de las constituciones liberales cambió radicalmente "los ámbitos y las materias" tuteladas con respecto a la intención de "regular las relaciones económicas de los actores públicos y privados" (Subirats, mayo-agosto, 1992, p. 29). Ello implicó el establecimiento de límites específicos al sector económico privado y su lógica de acumulación permanente, lo cual redundaba en una capacidad de redistribución de la riqueza social desde el Estado.

Acotado este punto indiscutible sobre el carácter del Estado Interventor y los supuestos que le confirieron vigencia y legitimidad, el proceso de desmantelamiento del mismo representa la continuidad del liberalismo. Por tanto, es pertinente reconocer esta gestión pública al calor de la contra-reforma del Estado costarricense bajo el concepto Neoliberal. Esta contra-reforma requirió de reformas constitucionales profundas y de reinterpretaciones de contenidos específicos de la Constitución de 1949, los cuales habían sido el producto de acuerdos concretos entre las clases y sectores sociales que protagonizaron el conflicto de la Costa Rica de la década de $1940^{16}$.

La imposibilidad de los partidos políticos para incorporar las demandas de los sectores afectados por la reestructuración liberal viene dada por la profundidad y ritmo de la contra-reforma del Estado costarricense. Precisamente, del pensamiento de Sartori se desprende un supuesto central que es puesto en tela de duda en esta investigación, es decir, ¿cuál es aquel que le confiere a los partidos políticos la posibilidad perenne de ser "conductos de expresión,

16 En los años noventa del siglo pasado, los sectores hegemónicos presentaron un proyecto de ley, bajo el nombre de "Garantías económicas", con el intentaban homologar el capítulo constitucional que contempla las garantías sociales. Se trataba de impulsar una mayor libertad para los agentes económicos (Mora, 1996). 
válidos y funcionales" para lo que se entiende como lo social? (Sartori, 2002, p. 212). Igualmente, esto abre el espacio para el análisis de las relaciones que establecen los partidos autodenominados "anti-neoliberales" con la diversidad de actores sociales que, desde la subalternidad, generan acciones colectivas de resistencia frente a lo hegemónico.

Esta desocialización es también una despolitización. El orden político ya no constituye, ya no funda el orden social ... Crisis de representatividad y de confianza que se acentuó a medida que los partidos se convertían cada vez más en empresas políticas que movilizaban recursos legales o ilegales, para producir elegidos que pueden ser "comprados" por los electores cuando éstos los consideran como defensores de sus intereses particulares, y a los que ya no podemos considerar como los agentes de la creación social (Touraine, 1994, p. 49).

Así, en la perspectiva de Touraine, si bien un actor social podría responder a su contexto y al proceso de exclusión/expropiación referenciado en esta investigación, ello no implica necesariamente que el mismo esté ligado "orgánicamente" al sistema de partidos. Por otra parte, lo que sí implica es que su acción social colectiva no siempre se encuentre supeditada a la incidencia en la toma de decisiones mediante el recurso de la representatividad formal.

\section{"La toma del poder" o la contradicción entre hegemonía y subalternidad}

Lejos de ser un personaje profético, un movimiento social es un conjunto cambiante de debates, tensiones y desgarramientos internos; está tironeado entre la expresión de la base y los proyectos políticos de los dirigentes

(Touraine, 2000, p. 105).

El debilitamiento del Estado nacional, por lo menos en sus funciones sociales, ha sido una consecuencia lógica de este proceso, en el que no solo se vació de sentido la política social, sino que se transfirió y continúa transfiriendo activos públicos al sector privado, con el fin de garantizar la acumulación permanente que es requerida por el capital. Esto ha extirpado del aparato del Estado su posibilidad de responder a demandas concretas y generales de sectores afectados por el proceso de exclusión/expropiación, el cual se fundamenta ideológicamente en lo que se conoce como neoliberalismo. En ese sentido, se indagó, en una forma específica de representación política, aquella que condensa la relación entre lo político y lo social, siendo que lo político genera a lo social desde un "imperativo que le es propio". Esta condensación de la relación se plantea con toda claridad en la "naturaleza de lo político" en el pensamiento de Sartori (2002, 2003a, 2003b, 2005a, 2005b).

Durante el proceso de acumulación de fuerzas del "Movimiento del No", la relación entre los grupos de actores y las/os actores individuales reveló una serie de tensiones que evidenciaban la imposibilidad de representar (políticamente) aquellos intereses generales que alimentaron dicho movimiento desde 
la diversidad de fuentes del conflicto. La explicación general de este conflicto se relaciona con las necesidades de reproducción del capital en lo que se conoce como "capitalismo tardío".

El recurso teórico-metodológico utilizado ubicó a los actores políticos "antineoliberales" de la Costa Rica del siglo XXI en el marco de lo que se ha denominado, para tal efecto, la "contradicción entre hegemonía y subalternidad", la cual requiere ser definida, a efectos de concretar su capacidad de explicar la relación entre lo político y lo social. La relación entre los actores sociales y los actores políticos, durante el contexto en estudio, generó tensiones y contradicciones. Estas tensiones y contradicciones revelan, en gran medida, la dificultad de conjugar, por un lado, las aspiraciones hegemónicas de los partidos políticos que se definen desde referentes distintos al neoliberalismo y que a su vez aspiran a acceder a la dirección del aparato del Estado y, por el otro, las aspiraciones y percepciones sobre la realidad de aquellos actores sociales articulados desde demandas particulares para enfrentar el avance de los procesos de exclusión social. Dicha exclusión tiene su explicación en la estrategia general del capital nacional y transnacional, pues se trata de sectores en situación de subalternidad, no solo en términos económicos, sino también políticos y culturales.

A esta dificultad estructural para conjugar los intereses, acciones y posicionamientos políticos se le ha denominado "contradicción entre hegemonía y subalternidad" en las tesis esbozadas en este artículo. Lo anterior redunda en la viabilidad de reproducción de lo político a través del mecanismo democrático-formal y liberal de la representación. Al menos tres hechos referidos a este contexto permiten poner en cuestión la viabilidad funcional de la relación entre lo "político y lo social" planteada por G. Sartori. Esta viabilidad se enfoca, especialmente, en la defensa de la representatividad como mecanismo democrático (Sartori, 2005b).

a. Se presenta el límite estructural que enfrenta la reproducción de "lo político" en este contexto. Los actores políticos (lejos de adscribirse a determinada clase social) se caracterizan por perseguir ejes programáticos que, posicionados en el discurso frente al neoliberalismo y la corrupción, no reparan si quiera en que el neoliberalismo no es un capricho de los sectores hegemónicos, sino la continuidad del proceso histórico de acumulación capitalista. En ese sentido, el Estado Interventor y su política social constituyeron solamente una discontinuidad en dicho proceso de acumulación y, ello al punto de que, como se ha acotado en este trabajo, se requirió de una serie de reformas durante la década de 1940 para establecer esos límites al capital.

b. Al acceder al poder político y colocarse al interior del ejercicio histórico de hegemonía en Costa Rica, los partidos "anti-neoliberales" se enfrentan con un Estado desmantelado como herramienta social, dado que el ejercicio hegemónico radicalizado del bipartidismo histórico, por la vía de la contra-reforma, 
ha vuelto a priorizar el liberalismo económico, institucionalizando lo que se conoce como pensamiento neoliberal.

c. A pesar de que las teorías de la democracia liberal representativa presuponen una relación funcional entre lo político y lo social -con autonomía de lo político sobre lo social- los partidos políticos, por su propia lógica, pueden llevar a la exacerbación el "imperativo propio" de lo político, suplantando el movimiento social en su intento de encauzarlo por la vía institucionalizada. Esto, en tanto que no todos los actores responden a este interés, sino, todo lo contrario, los reclamos de autonomía son un eje específico en muchas de las acciones colectivas del presente siglo (Touraine, 2000, p. 107).

Dado el carácter limitado, sobre todo en términos de extensión de un artículo de la naturaleza que nos ocupa y, a pesar de que la investigación que lo "alimenta", documenta tres momentos de la compleja relación entre lo que se considera político y lo que se considera social, en la polarización social que se conoció como "Movimiento del No", nos ocuparemos de documentar uno de los momentos de mayor tensión y contradicción entre ambos grupos de actores. Tres grandes fuentes de conflicto dentro del "Movimiento del No" fueron analizadas en el primer momento, definido como punto inflexivo para la "observación" de los dos conjuntos de actores determinados en el marco conceptual que se denominó "Contradicción entre hegemonía y subalternidad"17.Así, tres tipos de contradicciones se documentan en el Mapa reflexivo $\mathrm{N}^{\circ} 3$.

a. Aquellas que giraron en relación con "la salida" que debía tener un conflicto social que polarizó a la población. En este sentido, los actores políticos aglutinados en el Frente Nacional de Apoyo a la Lucha Contra el TLC, insistieron e impulsaron la idea de que el conflicto debía ser dirimido en un referéndum nacional, en tanto que al interior de la Coordinadora Nacional de Lucha, los actores sociales expresaban desconfianza en torno a la transparencia de dicho proceso.

b. En cuanto a la posición sobre el instrumento de libre comercio (CAFTA-RD), los posicionamientos políticos de los actores sociales, especialmente aquellos que se conformaron desde lo local, insistían en un rechazo total del instrumento, en tanto que varios de los actores políticos insistían en la renegociación del mismo.

c. En cuanto a las vías para hacer valer la agenda del "Movimiento de No", a saber, el rechazo a la incorporación de Costa Rica a la zona de libre comercio establecida mediante el CAFTA-RD, los actores sociales priorizaban distintos

17 Dado el volumen documental que alimentó la investigación, en este artículo se hace referencia únicamente al primero de los tres momentos definidos para la observación de la unidad analítica a saber: la relación entre actores políticos y actores sociales dentro del "Movimiento del No" (Primer momento inflexivo, de diciembre de 2006 a abril de 2007). Es precisamente el momento en que los actores políticos se aglutinan en una instancia paralela a la Coordinadora Nacional de lucha, el espacio organizativo de estos sectores surgió bajo el nombre: Frente de Apoyo a la Lucha Contra el TLC. 
repertorios de lucha. Sin embargo, los actores políticos insistían en las vías institucionalizadas y en los llamados constantes a la "paz".

Las contradicciones que, a manera de tensiones entre los distintos actores, se expresaron al interior del "Movimiento del No" son consecuencia directa de la incapacidad de los mecanismos de representatividad democrático-formales previstos por teóricos liberales o que comparten la matriz de pensamiento de Giovanni Sartori. Se trata de tensiones que provienen del enfrentamiento entre lógicas distintas, tal como es posible apreciar al tomar en cuenta que el mecanismo de la representatividad y los partidos políticos anti-neoliberales que priorizaron la esfera de lo político aún por encima de la base de movilización que tuvo el "Movimiento del No".

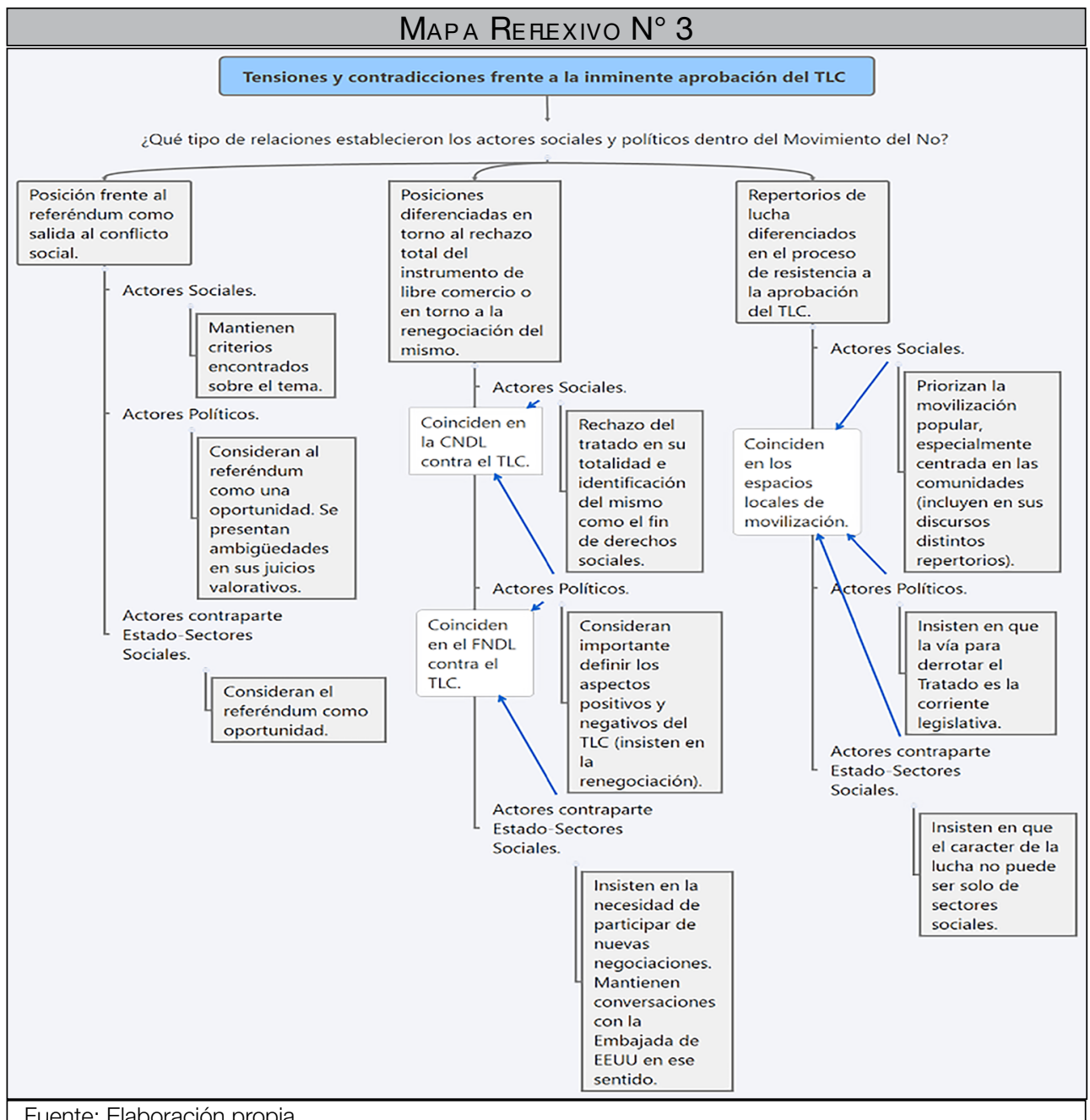


El principio de representatividad ha sido previsto con una determinada lógica, pues, tal y como lo plantea Sartori (2005b), "el significado originario de la 'representación' es la actuación en nombre de otro y para la defensa de sus intereses". Sin embargo, esa lógica corporativa de la representatividad no pudo aplicarse en la toma de decisiones dentro del "Movimiento del No", dada la multiplicidad de conflictos que ha

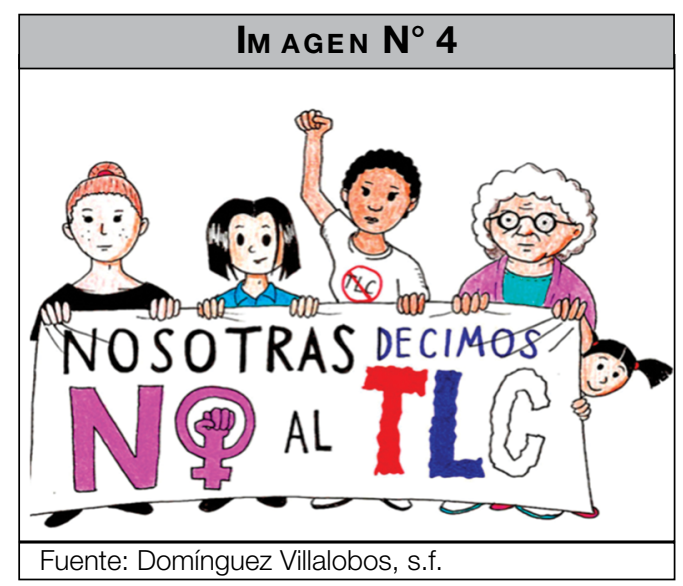
generado el proceso de acumulación capitalista y su lógica dialéctica de exclusión/expropiación. Las tensiones al interior del "Movimiento del No" revelaban una suplantación de la voluntad colectiva del movimiento por parte de los actores políticos, tal y como evidenciaron, mediante declaraciones públicas en varias oportunidades, voceros de la "Coordinadora Nacional de Lucha contra el TLC" (Comisión Nacional de Enlace, 2008).

Al respecto, G. Sartori le confiere centralidad al "uso sociológico" del concepto de representatividad, lo cual, en ese sentido y, a su juicio, revela "una idea de similitud, de identificación, de características compartidas" (Sartori, 2005b, p. 23). Con sagacidad, Sartori prevé posibles desencuentros entre representados y representantes en artículo intitulado "En defensa de la representatividad" (2005b). Sin embargo, tales desencuentros son atribuidos al "aumento de la población" y no a los cambios que provoca la modalidad de acumulación capitalista, exacerbada por el agotamiento de las fuentes de extracción de riqueza. En el caso que nos ocupa, a saber, respecto de las posibilidades de representación de intereses particulares o corporativos en nombre de movimientos sociales que responden a múltiples fuentes de conflicto, es difícil prever cómo podría llevarse a cabo esta representación por parte de actores políticos que se conforman desde una identidad "antineoliberal" y cuyo ámbito de acción es distinto al de los actores sociales, tal como quedó demostrado en la lucha "anti TLC".

Y a medida que los parlamentos van salvando el puente entre la sociedad y el Estado, entre transmitir exigencias (desde fuera) y tramitar exigencias (desde dentro), van adquiriendo un nuevo papel. Siguen hablando en nombre del pueblo pero han de hacerlo también en nombre del Estado; representan al pueblo pero deben también gobernar sobre el pueblo (Sartori, 2005 b, p. 30).

Debemos considerar que ya con anterioridad a este momento era harto complejo sostener que la representatividad aludía al "pueblo", sobre todo en tanto las teorías de la democracia formal se encontraban referidas a una relación entre lo político y lo social en contextos en que el Estado Interventor 
gozaba de un cierto margen para "desviar" recursos hacia la reproducción de "lo social". Sin embargo, durante todo el proceso de acumulación de fuerzas y acciones colectivas de rechazo al TLC (o CAFTA-RD), los desencuentros provocaron múltiples tensiones, revelándose intereses y formas distintas de abordar el conflicto por parte de ambos grupos de actores.

Tal y como se ha sostenido a lo largo de este artículo, no es posible representar al Estado y al pueblo al mismo tiempo, tal como propone Sartori. Si ello era difícil de probar en el contexto del Estado Interventor, lo sería imposible frente a un Estado que tutela la reestructuración neoliberal institucionalizada, la cual se presenta como necesaria y estructural en este contexto. Más allá aún, la lógica de los actores sociales tenía y tiene hasta hoy un asidero netamente local y es justo en lo local, donde las comunidades reaccionan y se subjetivan frente al ejercicio hegemónico radicalizado, cuya lógica es, como ya mencionamos, garantizar la continuidad de la acumulación capitalista.

Además, la esfera de acción natural de los actores partidarios (actores políticos) es, sin lugar a dudas, el Estado. Sin embargo, de acceder a la dirección del mismo como

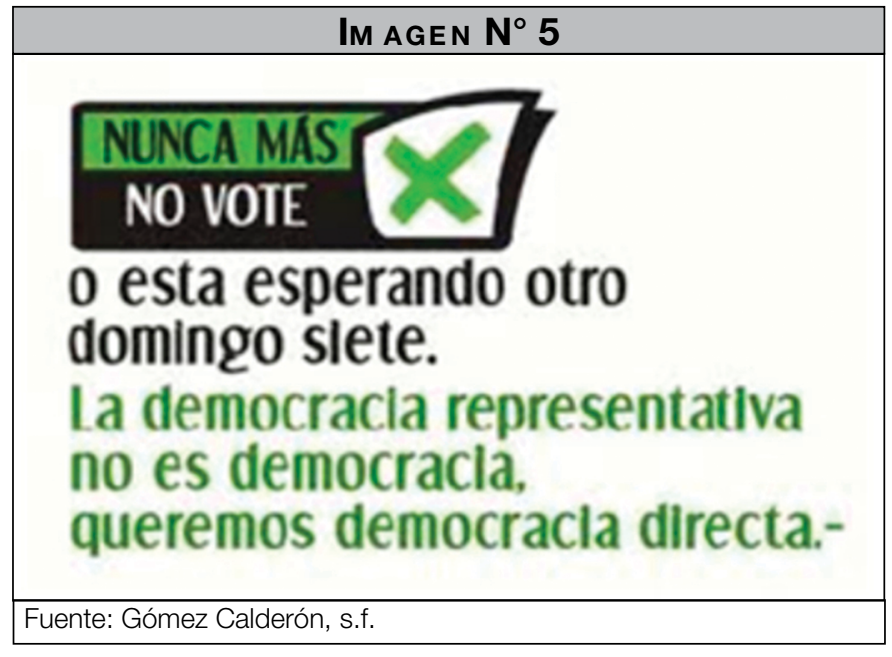
alternativa real, ya sea mediante escaños legislativos o puestos de control ubicados en la dirección del mismo (Poder Ejecutivo), el margen de acción para incorporar demandas de actores sociales es bastante escaso, precisamente, por el desmantelamiento de lo que se conoció como Estado Social. Es a este complejo fenómeno al que hace referencia esta propuesta de investigación bajo la relación conceptual: "contradicción entre hegemonía y subalternidad".

Por esta razón, para los efectos del presente trabajo, se define al Estado, por lo menos en términos históricos, no solo desde su capacidad para ejercer el monopolio legítimo de la violencia y/o sus posibilidades de ejercicio coercitivo, sino también atendiendo a su capacidad de generar consensos: es en esta segunda importante función en la que el Estado Neoliberal se debilita.

Uno de los más grandes desencuentros entre actores sociales y actores políticos en el contexto en estudio, giró en torno a la aceptación o no de los resultados del Referéndum Vinculante convocado por la administración Óscar Arias Sánchez 
(2006-2010) (Comité Cívico de Occidente, 2007). Sin embargo, y a pesar de que dos Asambleas Nacionales de Comités Patrióticos rechazaron la aceptación de los mismos, pasando a denunciar irregularidades de forma y fondo en el proceso, los resultados fueron aceptados la propia noche del 7 de octubre por Eugenio Trejos ${ }^{18}$, como coordinador de lo que se conoció como "Movimiento Patriótico"19.

La compleja relación entre lo político y lo social en la Costa Rica del siglo XXI revela el ensanchamiento de una brecha estructural e histórica, la que en este contexto, expresa los límites de las teorías liberales de la democracia formal, pero sobre todo, de las condiciones de reproducción "armoniosa" del sistema social, es decir, la posibilidad de continuar sosteniendo la legitimidad de los sectores hegemónicos, independientemente de su afiliación ideológica. En este sentido, la legitimidad de los sectores hegemónicos ya no puede partir de presentar al Estado como una "comunidad ilusoria", tal y como ha llegado a puntualizar el investigador Jaime Osorio (2004).

\section{Referencias}

Bermúdez, Mario. (24 de octubre de 2004). Gobierno varió composición y pasó del choque al pacto. El Financiero. Recuperado de http://wvw.elfinancierocr.com/ef_archivo/2004/octubre/24/informe1.htm \|

Blanco Lizano, Randall. (2010). Transformaciones del sector exportador costarricense en la transición del modelo de sustitución de importaciones al modelo de libre comercio: 1981-1996. Estudio de caso de las redes imbricadas de agentes público-privados-CINDE-COMEX (Tesis para optar por el grado de Doctor en Gobierno y Políticas Públicas). Universidad de Costa Rica, San José, Costa Rica.

Comisión Nacional de Enlace. (2008). El Movimiento Social Costarricense y la Lucha contra el Tratado de Libre Comercio: Balance y conclusiones del proceso. Recuperado de http://www.aporrea.org/internacionales/a87595.html

Domínguez Villalobos, María de la Claridad. (s.f.). La cazadora (dibujo gráfico).

Domínguez Villalobos, María de la Claridad. (s.f.). Nosotras decimos no al TLC (dibujo gráfico).

Domínguez Villalobos, María de la Claridad. (s.f.). Todxs nosotrxs decimos ¡No! al TLC (dibujo gráfico).

Gómez Calderón, César Augusto. (s.f.). Alí Baba y los 38 ladrones (dibujo gráfico).

18 Eugenio Trejos fungió como candidato presidencial del Frente Amplio en el proceso electoral 2010-2014.

19 Esta información fue recuperada de un volante titulado "Alerta quieren boicotear Asamblea" y fue repartido el 10 de octubre de 2007. 
Gómez Calderón, César Augusto. (s.f.). Nunca más, no vote (la democracia es el gobierno del pueblo) (dibujo gráfico).

Jiménez M., Gustavo. (28 de enero de 2003). Negociación de TLC se inició con tono bajo. La Nación. Tomado de http://wvw.nacion.com/ln_ee/2003/ enero/28/pais1.html

Mandel, Ernest. (1979). El capitalismo tardío: El hombre y su tiempo. México, D.F.: Ediciones Era.

Matute, Ronald. (24 de diciembre de 1995). Congreso marchó a ritmo de pacto. La Nación. Recuperado de http://wvw.nacion.com/In_ee/1995/diciembre/24/pagina04.html

Modonesi, Massimo. (2010). Subalternidad, antagonismo y autonomía. Marxismo y subjetivación política. Buenos Aires: Consejo Latinoamericano de Ciencias Sociales-CLACSO / Prometeo Libros.

Mora, Henry. (1996). Garantías económicas: ¿Hacia una política económica neutral? Economía y Sociedad, 1(1), 1-15.

Offe, Claus. (1988). Partidos políticos y nuevos movimientos sociales. Madrid: Editorial Sistema.

Osorio, Jaime. (2004). El Estado en el centro de la mundialización. México D.F.: Fondo de Cultura Económica.

Raventós, Ciska. (2008). Balance del referendo sobre el TLC en Costa Rica a la luz de la teoría de la democracia. Revista Ciencias Sociales, 121(III), 13-29.

Raymer, Jeremy. (2008). Vecinos, ciudadanos y patriotas: los comités patrióticos y el espacio temporalidad de oposición al neoliberalismo en Costa Rica. Revista de Ciencias Sociales, 121(III), 71-87. Recuperado de http:// www.redalyc.org/articulo.oa?id=15311737005

Sartori, Giovanny. (2002). La política. Lógica y método en las ciencias sociales (Trad. Marcos Lara). México D.F.: Fondo de Cultura Económica.

Sartori, Giovanny. (2003a). ¿Qué es la democracia? Madrid: Taurus.

Sartori, Giovanny. (2003b). La Influencia de los sistemas electorales. En B. Grofman y L. Arend (eds.), Electoral Laws and Their Political Consequences. Recuperado de http://wvw.nacion.com/In_ee/1995/diciembre/24/pagina04.htm

Sartori, Giovanny. (2005a). Partidos y sistemas de Partidos. Madrid: Alianza Editorial, S.A. 
Sartori, Giovanny. (2005b). En defensa de la representación política. En Miguel Carbonell (comp.), Democracia y representación: un debate contemporáneo (pp. 21-34). México D.F.: Tribunal Electoral del Poder Judicial de la Federación.

Subirats, Joan. (Mayo-Agosto, 1992). El proceso de formación de políticas en España, algunas hipótesis. Revista del Centro de Estudios Constitucionales, (9), 199-216.

Tasies, Esperanza. (2015). Actores políticos y actores sociales: contradicción y tensiones en el proceso de resistencia al Tratado de Libre Comercio entre Centroamérica, República Dominicana y los Estados Unidos de América. Costa Rica 2006-2010 (Tesis de Maestría en Sociología). Universidad de Costa Rica, San José, Costa Rica.

Touraine, Alain. (1994). Crítica a la Modernidad. Buenos Aires: EFE.

Touraine, Alain. (1999). ¿Cómo salir del liberalismo? España: Ediciones Paidos lbérica.

Touraine, Alain. (2000). ¿Podremos vivir juntos? México: Fondo de Cultura Económica.

Wallerstein, Immanuel Maurice. (2004). Capitalismo histórico y movimientos antisistémicos: Un análisis de sistemas-mundo (traducción de Juan María López de Sa y Madariaga). Madrid: Ediciones AKAL. 